\title{
QSCIENCE PROCEEDINGS
}

\section{OPEN ACCESS}

Lightning Talk

Lisbon University, Portugal

2Leiden University, Netherlands

3 University of Sheffield, UK

Research on Research Institute, UK

*Email:s.oliveira@cwts.leidenuniv.nl

https://doi.org/10.5339/qproc.2022. ehil2021.7

Published: 13 January 2022

(C) 2022 The Author(s), licensee HBKU Press. This is an Open Access article distributed under the terms of the Creative Commons Attribution license CC BY 4.0 (https:// creativecommons.org/licenses/ by $/ 4.0$ ), which permits unrestricted use, distribution and reproduction in any medium, provided the original work is properly cited.

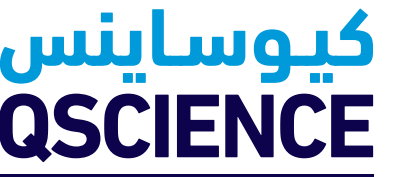

The Evolving Health Information Landscape Symposium-

December 2, 2021-Virtual Doha

\section{Scholarly Publishing and Peer-review in Times of Crisis: An Overview}

\author{
Susana Oliveira Henriques ${ }^{1,2.4}$, Ludo Waltmann,4, Stephen Pinfield3,4, \\ Narmin Rzayeva ${ }^{2,4}$
}

Abstract

We present the main conclusions, lessons learned, and recommendations of the work carried out in the COVID-19 Rapid Review Initiative, published in a detailed report (https://doi.org/10.6084/m9.figshare. 17125394.V1), prepared by the Research-on-Research Institute (RoRI, http://researchonresearch.org/) in collaboration with researchers, publishers, and other scholarly communication experts.

The coronavirus pandemic has highlighted the importance of an effective scholarly communication system. Traditional scholarly communication channels, particularly peer-reviewed journals, have been put under pressure to deal with Covid-19-related research in a timely way. At the same time, some alternative channels of scholarly communication have received more attention during the pandemic, partly in terms of the role they can play in easing pressure on traditional publication channels. One major alternative channel of scholarly communication is that of preprints. Preprints have become an essential part of the communication of research about Covid-19, but concerns remain about quality assurance, which is clearly associated with the recent emergence of new projects that streamline evaluative peer interactions (e.g., comments, recommendations, reviews) on Covid-19 preprints.

These innovative projects center on providing a more transparent and rapid peer review process, improving the scientific publication workflow, offering different publication options to authors, and ensuring that research (Covid-19 or non-Covid-19) becomes more widely available, more transparent, and credible. Based on the lessons learned from the Covid-19 Rapid Review Initiative, we discuss the challenges and opportunities that these projects create for different stakeholders, especially researchers, publishers, funding agencies, and science policymakers, both in the Middle East and elsewhere.

Keywords: Scholarly communication, scientific publishing, innovation, preprinting, peer-review
Cite this article as: Henriques SO, Waltman L, Pinfield S, Rzayeva N. Scholarly Publishing and Peer-review in Times of Crisis: An Overview. QScience Proceedings-The Evolving Health Information Landscape Symposium 2021, Qatar- 2022(1):7. https://doi.org/10.5339/qproc.2022.ehil2021.7. 